\title{
El arte de vituperar
}

\author{
The Art of Vituperating
}

A arte de reprovar

\section{Jean Franco}

COLUMBIA UNIVERSITY, ESTADOS UNIDOS

Profesora emérita de Columbia University, Nueva York, Estados Unidos.

Autora de The Modern Culture of Latin America (Penguin Books, 1967); César Vallejo. The Dialectics of Poetry and Silence (Cambridge University Press, 1976); An Introduction to Latin American

Literature (Cambridge University Press, 1969); Plotting Women.

Gender and Representation in Mexico (Columbia University Press, 1989); Marcar diferencias/cruzar fronteras (Cuarto Propio, 1996);

The Decline and Fall of the Lettered City: Latin America and the Cold War (Harvard University Press, 2001); Cruel Modernity (Duke University Press, 2013). Correo electrónico:jf29@columbia.edu

\section{Artículo de reflexión}

Documento accesible en línea desde la siguiente dirección: http://revistas.javeriana.edu.co doi:10.11144/Javeriana.CL19-37.eadv 


\section{Resumen}

En el presente artículo, Jean Franco analiza $E l$ desbarrancadero y El don de la vida para establecer un contraste entre los lamentos de Vallejo. Franco reconoce que en estas dos obras Vallejo pasa del elogio de lo humano, materializado en el amor hacia su hermano Darío, al lamento descarnado por la pérdida de la humanidad entera. La autora utiliza el cambio de marco de Vallejo y el estilo del memento mori para reflexionar sobre lo que sigue siendo tan provocativo de la obra de Vallejo.

Palabras clave: Fernando Vallejo; El desbarrancadero; $E l$ don de la vida; memento mori; ; feminismo; humanismo

\section{Abstract}

In this article, Jean Franco analyzes El desbarrancadero and El don de la vida in order to establish a contrast among Vallejo's lamentations. Franco acknowledges that, in these two works, Vallejo moves from praising what is human, materialized in the love for his brother Darío, to the brutal lamentation due to the loss of the whole humanity. The author uses the change of framework made by Vallejo and the 'memento mori' style to reflect upon what keeps being so suggestive about Vallejo's work.

Key words: Fernando Vallejo; El desbarrancadero; El don de la vida; memento mori; feminism; humanism

\section{Resumo}

No presente artigo, Jean Franco analisa El desbarrancadero e $E l$ don de la vida para estabelecer um contraste entre os lamentos de Vallejo. Franco reconhece que nestas duas obras Vallejo passa do elogio do humano, materializado no amor por seu irmão Darío, ao lamento descarnado pela perda da humanidade inteira. A autora utiliza a mudança de marco referencial de Vallejo e o estilo do 'memento mori' para refletir sobre o que continua sendo tão provocativo na obra de do autor.

Palavras-chave: Fernando

Vallejo; El desbarrancadero; $E l$ don de la vida; memento mori; feminismo; humanismo

RECIBIDO: 5 DE JUNIO DE 2014. EVALUADO: 19 DE JUNIO DE 2014. DISPONIBLE EN LÍNEA: 15 DE ENERO DE 2015.

\section{Cómo citar este artículo:}

Franco, Jean. "El arte de vituperar". Cuadernos de Literatura 19.37 (2015): 177-184. doi:10.11144/Javeriana.CL19-37.eadv 
"A mí que no me vayan a promover homenajes cuando me muero que ya no los quiero. Ni crucifijos, ni flores, ni entierro, ni ninguna de esas faramallas"

El don de la vida

EN El fuego secreto, Fernando Vallejo escribe: "la vida cuando se empieza a poner sobre el papel se hace novela" (8). Sin embargo, El don de la vida, como la mayoría de su obra, es más vituperio que novela. La vituperación es lo opuesto al diálogo. No tiene respuesta ni hay réplica posible. En su forma escrita, en la obra de Vallejo deja a los lectores en una curiosa situación entre cómplices involuntarios o críticos impotentes. En 2013, la publicación de una colección de ensayos con el título Peroratas confirma el proyecto de fabricar un discurso que desafía las preferencias liberales por el diálogo o, por lo menos, por el simulacro del diálogo. Los lectores no son participantes, sino recipientes de unas denuncias que no permiten respuesta.

Los blancos son variados e incluyen a las madrecitas de Colombia, a los muchachos de Colombia y a los amores prohibidos. Curiosamente, como se puede averiguar de un video filmado durante una caminata nocturna por las calles de Bogotá, ${ }^{1}$ este profeta de fulminantes sentencias no ha perdido la admiración y respeto de sus compatriotas, a pesar de su crítica y a pesar de su emigración a México, lejos de su país natal. En otro video, se ve al escritor solo en la tribuna compartiendo con un público, en su mayoría joven, sus numerosas antipatías que incluyen la religión cristiana y a los que maltratan los perros ("El sermón del Anticristo"). Habla en una voz monótona dando una lista de quejas como una comadrona en el mercado, lo que me hace preguntar por qué atrae tanto a la gente. Y se me ocurre que en nuestro mundo dicho posmoderno y aparentemente democrático falta una tribuna desde donde se pueda expresar la inconformidad radical para con este mundo, con la religión, con la política y con la vida misma. Las quejas de Vallejo van más allá de la política: atacan la civilización entera que, según él no tiene ni propósito ni mucho menos sentido. Y como no varían mucho sus odios y son los mismos desde sus primeros libros hasta el más reciente, me limito a comentar El don de la vida, cuyo título hay que leer como referencia irónica. Como todos sus libros es un lamento por lo efímero de las cosas y especialmente por los seres humanos y sus pertinencias. Aunque está escrito en forma de diálogo con don Álvaro Jaramillo Echeverri Restrepo,

1 El escritor Fernando Vallejo caminando por las calles de Bogotá, 17 de octubre de 2010. Se puede encontrar las entrevistas de Vallejo en la red. 
en realidad don Álvaro sirve solo como compañero de ruta en una caminata al vacío. En esta conversación, Vallejo varias veces se muestra nostálgico por Santa Anita, la finca de la familia: "Me creerán que cuando volví a Santa Anita a ver qué quedaba de la finca de mis abuelos y mi niñez y solo descubrí esas piedras me salieron las lágrimas" (20).

No es de sorprenderse, por lo tanto, que El don de la vida sea una variación de la tradicional Ubi sunt?, y un memento mori que nombra "La Muerte, la Vejez y el Tiempo" como "los máximos instrumentos de Dios" (27).

Aunque Vallejo escribe en México porque, como dice, "no sé dónde meterme en el planeta", su escritura está anclada en la provincia de Antioquia y en su capital Medellín y en la familia en cuyo seno cunden odios, amores y resentimientos. La suya era una familia dedicada a la procreación: los veinte hijos de la Loca, la madre procreadora, para Vallejo, demuestran el exceso y la insensatez de la procreación en un país afligido por el tráfico de drogas, por las guerras internas y por la violencia. Con razón el crítico, Christopher Domínguez Miguel, ha nombrado a Vallejo "El Céline de la violencia latinoamericana".

Aunque la portada de su libro El desbarrancadero lleva una fotografía de Fernando chico abrazando amorosamente a su hermanito Darío, esta imagen de la inocencia es denegada por la historia de la muerte de Darío de sida, que Vallejo describe en detalle en El desbarrancadero. La degeneración de su hermano hospedado en el piso bajo de la casa y alejado de la madre la Loca, quien camina arriba, va a la par con la degeneración de la provincia, de la naturaleza y un campo invadido por la ciudad.

El don de la vida es, por lo tanto, un memento mori para todos sus conocidos y para la humanidad en general. Es también un lamento por la degeneración de Antioquia, debido al crecimiento de Medellín, que ha transformado los escenarios de la juventud y ha hecho imposible el amor para un país natal que ya no existe. La ciudad de su infancia "era un jardín botánico regado por un río de plata. Hoy el río es un sumidero de alcantarillas y el jardín botánico un terrenito de unas cuantas cuadras conservado para recordarnos que la felicidad pasó por aquí y se fue" (143). Entre las fincas tumbadas se contaba la de Santa Anita, que había sido propiedad de la familia y que para Vallejo era "el sueño del paraíso" antes que su tío Argemiro la perdiera y la cambiara por un carro, "el carro por una moto, la moto por una bicicleta y la bicicleta por unos patines que tiró al río" (30). Esta minihistoria resume la degeneración que es asociada con las "mentiras" de la creencia religiosa y la nacionalidad. Como él mismo constata, "no es comida lo que quiero vomitar. Es a Colombia, a mi familia, al loco Cristo... Toda esta mentira nauseabunda que me metieron adentro y que me está envenenando las tripas" (115). 
Soy feminista. Leer la obra de Fernando Vallejo siempre me hunde en un mar de contradicciones entre admiración y desacuerdo, aunque comparto algo de su pesimismo sobre el futuro de la humanidad. Queda claro que el blanco de la ira de Vallejo va más allá de la familia antioqueña y más allá de la nación, más allá de Colombia con sus guerras civiles, con la violencia y el exceso de población; más allá de la destrucción del ambiente, el sufrimiento de los perros y lo absurdo de la religión católica. Su blanco es la vida misma, el "don" de la vida. Le gusta la paradoja de este título que da a una crónica que conmemora no solamente a los muertos, sino también a la muerte, a los paisajes desaparecidos, las fincas destruidas por la construcción de edificios "donde hacinar a la chusma desfondada que seguía pariendo" (24). En vano busca una justificación de la existencia humana: "el hombre es una máquina programada para eyacular y los demás son cuentos" (37), asevera. No se salva la literatura "invadida por una caterva de novelistas damnificados y serviles, maestros en el arte de adular al lector y mendigarle su benevolencia en tanto ansían premios literarios, reconocimientos y honores" (137).

De esta lista de enemigos se deduce que Vallejo no está de acuerdo con la modernidad, que considera un desastre sin remedio, lo que lo aleja de las que, como yo, todavía espera (aunque cada día menos), que la civilización triunfe.

En El don de la vida, el autor de tales rumiaciones (el Fernando imaginado) las emite desde una banca de viejos que comparte con su amigo Álvaro en un parque de Medellín, donde circulan "mendigos, prostitutos, prostitutas, chantajistas, estafadores, lustradores de zapatos, vendedores de lotería, expendedores de droga, travesties, raponeros" (48-9) y desde donde puede admirar a los jóvenes y recordar sus conquistas. Es un lugar privilegiado desde donde ve pasar a todo Medellín mientras fulmina contra la vida y la muerte, contra mujeres carnívoras y las que ocupan puestos públicos y hasta contra las "mamarrachadas del ballet". Su compañero observa con razón "lo que usted propone es una religión pederasta, misógina y vegetariana"; pero no puede parar al chorro de opiniones que duran toda la tarde hasta el anochecer y cuyo tema es "la humanidad sí avanza pero retrocediendo" (135).

El don de la vida es también un libro de recuerdos, un memento mori que nombra a los que mataron y los que murieron en la cama. El autor no inventa, sino que actúa como escribiente para confeccionar una larga lista de muertos cuyos nombres escribe en su libreta, donde en otros tiempos anotaba una lista de muchachos que rivalizaba al catálogo de mujeres de don Giovanni — "ingleses, franceses, españoles, negros, árabes bereberes. Pero en su mayoría colombianos" (36-7) —. Incluye en el libro de muertos también a los perros — "mi perra Argia, mi perra Bruja, mi perra Kim y mi perra Quina" (152), que declara sus más grandes amores junto con la abuela Raquel y la finca Santa Anita-. 
Su mayor goce es insultar a las vacas sagradas - a la madre, por supuesto, a Bolívar el Libertador, a los papas, al "payaso" Sigmund Freud, al "asqueroso" Octavio Paz y a algunos menos conocidos como Magnus Hirschfeld, pedófilo, y Armando Bo, "productor y director de películas pornográficas". Y le da placer insultar a "esta alcahuetería de los derechos humanos" o al papa Juan Pablo Segundo, el "papa mierda" o a Borges, "Viejo güevón que no pichó. Ni con vivo ni con muerto, ni con hombre ni con mujer, ni con perro ni con quimera". A Cristina Kirchner la describe como un "engendro de vulgaridad y oportunismo salido de las trompas de Falopio de la Gorgona".

Su método es sencillo: decir lo contrario de toda opinión generalmente aceptada, por ejemplo, la bondad del campesino que Vallejo expone como "el mito más descarado e impúdico que haya parido en su insania, la mentira. Ellos llevaron a cabo la Violencia, la que se dejará azuzar en sus podridas almas por los políticos" (111). Obviamente no hay respuesta posible a estas sentencias y a los lectores los dejan mudos. Lo cierto es que Vallejo está vomitando opiniones, como el mismo reconoce, aprovechando de una tribuna que no tiene espacio para la respuesta.

Declarando que solo el presente existe que no hay pasado ni futuro, pasa las horas en el parque recordando a los muertos y riéndose de ellos. "Y hoy, después de mucho que ha llovido y arrastrado agua el río, me sigo riendo de esta sociedad astrosa" (127). La lógica (si podemos nombrarla tal) lo conduce al elogio de la muerte que condena a los vivos a ser "bípedos fugaces, pasajeros". La muerte es "la bendición de Dios. Lo único bondadoso y que nos ha hecho en catorce mil millones de años que lleva supervisando el mundo ese viejo Marica" (156).

Sin embargo, se nota la nostalgia por la religión, a pesar de sus afirmaciones de ateo. ¿Cómo se explican de otra manera los rezos al Padre Eterno, el elogio a la Catedral, la nostalgia por los muertos? Si ya no le dice nada la religión católica, por lo menos, le ha enseñado las prácticas que le permiten rezar por los pecadores, entre los cuales incluye los barrios de tolerancia de Medellín. "Barrio de Lovaina. Requiescat en pace etc.". A pesar de que quiere "vomitar a Colombia, a la familia, al loco Cristo" (115), es como si no pudiera deshacerse completamente de ellos. Por eso me pregunto, si un ateo que no cree en Dios puede cometer un sacrilegio (aquí empleo la lógica de Vallejo que convierte cada negación en afirmación o viceversa). "Después de mí el diluvio" es una de sus oraciones, la última del libro.

La homosexualidad de Fernando, tan celebrada en sus libros, es no solo un desafío a la supuesta normalidad, sino una reacción contra la sobrepoblación y contra la excesiva y exagerada masculinidad. Su amor a los perros es una reacción 
contra una humanidad pervertida y una religión absurda. En El don de la vida describe la pareja como "turba infecta" y quiere "un paredón para el que se reproduzca" (35). Describe su tarea como la de limpiar maleza. Pero es también el espíritu de la venganza que le hace bajar de sus sitios privilegiados a los famosos, al escribir la lista de los muertos en orden alfabético.

La lista de sus odios se vuelve cómica. Denuncia hasta los teléfonos celulares. "Ahí van pegados a esos aparaticos imbéciles los bípedos zafios de esta raza tarada caminando como zombis parlantes" (49). Desde su punto de vista, "el hombre es una máquina programada para eyacular y lo demás son cuentos" (37). Aunque registra la muerte de la abuela y luego de la Bruja y su hermano Darío, lo que parece que le duele más es la pérdida de su sueño del paraíso, un paraíso de este mundo que era la finca de Santa Anita. Lo que le queda de herencia es "humo, viento, mierda" (29).

La destrucción de la familia y la finca va a la par con la destrucción del país, que está "dividido entre dos partidos" y donde "no quedan sino los muertos, algunos sin cabeza y otros sin contar"; muertos echado a ríos que ahora se secan porque "los mataron con la tala de árboles y los borraron del mapa como piensan que me van a borrar a mí pero se equivocan, porque si los ríos pasan la palabra queda". La duración de la palabra es la única esperanza en este mundo atestado, "el infierno atestado, el cielo atestado, el purgatorio atestado, el limbo atestado, la calles atestadas, los hospitales, los restaurantes atestados. Gente y más gente y más gente cagando, cagando y cagando" (57). La ciudad de Medellín ha degenerado hasta convertirse en "ruinas de ruinas". "La ruina económica, social, espiritual, moral, total" (62).

El don de la vida es el libro donde reitera todas las antipatías y odios. En cambio, El desbarrancadero es la crónica de la agonía de su hermano Darío, enfermo de sida; una agonía que carece del heroísmo que en los Estados Unidos otorgaba una suerte de nobleza a los enfermos y donde se representaba la enfermedad como un problema político que se discutía en reuniones, en el teatro y en la literatura. En cambio, Darío sufre aislado en la casa familiar donde la degeneración física priva su sufrimiento del dramatismo. Sin embargo, Darío es el fantasma que ronda alrededor de la obra, el fantasma que acusa a Fernando y que el humor no llega a suprimir.

Aunque me gusta leer los libros de Vallejo, gracias a internet puedo escucharlo hablando en la Feria del Libro de Guadalajara o en otras reuniones donde denuncia la injusticia, la política vergonzosa, la crueldad. En un mundo donde la televisión ha captado la noticia y las opiniones, es importante que haya encontrado una tribuna desde donde pueda seguir vituperando. 


\section{Obras citadas}

Vallejo, Fernando. El desbarrancadero. Barcelona: Alfaguara, 2001.

-. El don de la vida. Barcelona: Alfaguara, 2010.

-. El fuego secreto. Buenos Aires: Alfaguara, 2005.

-. Peroratas. Barcelona: Alfaguara, 2013. 